in their opinion the workers are doing more toward national defence than if they were on active military service. These are : medicine and allied professions, biological sciences, chemistry, physics, geology and related earth sciences, and engineering in all its branches. Commenting on the desirability of such deferments, the committee points out: "Experience of every nation engaged in the World War and the conditions under which the present conflict in Europe is being waged point directly to the necessity for proper employment of scientific personnel and of those competent to train such personnel, to a continuous supply of newly trained personnel, and to the penalties incident to assigning them in large numbers to purely military service where others without their special training can function equally well."

Particular stress is laid on the desirability of permitting students in such fields as medicine, dentistry, and pharmacy to finish their courses before they take up their military duties, because of the large demand for trained men in both the military and civil sectors, and because intensive specialized training cannot make up for a deficiency of qualified personnel. In all six fields, the statement continues, university presidents should request deferment of members of the teaching staff who in their judgment are essential properly to maintain the efficiency of the institution in the continuous training of students necessary in the operation of the defence programme or in the effective conduct of research and development problems assigned to the institution in connection therewith. The industrial laboratory and some graduate schools employ trained personnel often in group or team operations which require not only highly skilled. individual scientific workers and engineers but likewise men accustomed to working together in close co-operation. Subtraction of a single key man from such a group may seriously handicap or even substantially destroy the efficiency of the group to function. The problem of the industrial and university research laboratory concerned with a present or prospective defence programme is not only one of retaining an adequate number of highly trained research men, engineers and skilled technicians, but also one of maintaining the integrity of research and development teams. This is because industrial research and development is a co-ordinated group activity. Research directors should request deferment of highly qualified men whose training and experience are such that their withdrawal will cripple the ability of the laboratory to function effectively in the defence programme.

\section{Engineering Courses for Students in H.M. Forces}

IN the December issue of the Journal of the Institution of Civil Engineers and in that also of the Institution of Mechanical Engineers, there are announcements regarding the plans which are being made to provide technical instruction for engineers serving in the Fighting Forces. During the War of 1914-18, there was a break in the studies of a whole generation of engineers, with the most serious consequences to the profession and to those young men who, on attempting to resume their training, had difficulty in pursuing their studies and in passing the qualifying examinations. They were, in so many cases, severely handicapped at the most vital stage in the making of their careers. The two Institutions mentioned and the Institution of Electrical Engineers are co-operating with the Board of Education and the Council for Education in the Forces in the organization of courses in engineering subjects.

Curricula of work suitable for guided reading or correspondence courses are now in preparation in some sixteen subjects and are to be of a standard in accordance with the examination requirements of the three Institutions. The subjects chosen are those which have proved most popular among candidates, but it is indicated that other subjects could be included if there is a sufficient demand. There is a suggestion, too, that the new arrangements will provide the means of keeping abreast with their studies for those who were following courses leading up to National Certificates. Relaxation of the "castiron' system on which these certificates are founded will, however, be necessary, or otherwise candidates will find themselves on demobilization barred from both examination and reward by lack of some qualifying percentage of attendance or other ephemeral aspect of training.

The announcements make it clear that while in some respects the serious educational position into which we are drifting is realized, it is only being tackled on the more spectacular side. Here it should be noted that the prime movers are not the critically interested parties, the Board of Education and the professional institutions. The scheme has been initiated by the Council for Education in the Forces. This has the disadvantage that, the arrangements being exclusively for those serving in the Forces, the organization is powerless to assist others. It must be well known, however, that there are many thousands of young men in the engineering industry who, in these days, cannot pursue their studies in the ordinary way. This is a class of student whose progress is seriously hindered by any break in his course of study, as is made clear by the regressive effect of the summer vacation. New systems of education cannot be brought into working order at short notice, and, if not taken in hand now, the position in three years' time will be considerably more serious than in 1919. It is to be hoped, therefore, that a more enlightened policy may emerge, charged with greater sympathy for the difficulties of the younger generation of engineers.

\section{Science and Government}

AT a meeting of the Watford Branch of the Association of Scientific Workers held jointly with the University College Hospital Medical School Socialist Society on January 23, Prof. J. D. Bernal spoke on "Science and a New World Order". Prof. Bernal made a survey of the present relations of science with government, particularly dealing with the position of advisory committees. Since the processes of Nature (in the widest sense) are intract. 